\title{
A Ghost in the Machine? Politics in Global Health Policy
}

\author{
Carlos Bruen $^{1^{*}}$, Ruairí Brugha ${ }^{2}$
}

\author{
*Correspondence to: Carlos Bruen, Email: carlosbruen@rcsi.ie \\ Copyright: $\odot 2014$ by Kerman University of Medical Sciences \\ Citation: Bruen C, Brugha R. A Ghost in the Machine? Politics in Global Health \\ Policy. Int J Health Policy Manag 2014; 3: 1-4. doi: 10.15171/ijhpm.2014.59 \\ Received: 11 June 2014, Accepted: 24 June 2014, ePublished: 25 June 2014
}

$\mathrm{M}$ embers of the $67^{\text {th }}$ World Health Assembly in 2014 were presented with a framework document to guide World Health Organization (WHO) engagement with non-state actors, a key part of WHO reform kick-started in 2011. According to this document, non-state actors include four distinct constituencies: i) nongovernmental organizations (NGOs), ii) private sector entities; iii) philanthropic foundations; iv) academic institutions (1). While the WHO has collaborated in a variety of ways with non-state actors since its foundation, a comprehensive policy for engagement has remained elusive and politically fraught. Some commentators are concerned that a more formal engagement will strengthen the already undue influence of well-resourced non-state actors, particularly companies, who seek to influence policy and priorities through extrabudgetary project funding (2). The World Health Assembly has requested the WHO Secretariat to go back and develop the policy further, leaving the organisation without clear guidelines on how it is to engage with non-state actors.

Among the many criticisms levelled at the WHO, a persistent claim has been that it has become overly bureaucratic and overly politicised, leading one critic to remark that "it is where good ideas go to die" (3). According to former Director General Jack C Chow, the WHO is bogged down by the need for consensus, is primarily responsive to the disease-specific interests of donors, and suffers from an archaic governance system more akin to a federation of six regional offices (4). For Chow, the WHO risks becoming irrelevant, stagnating in a world where public health is changing rapidly. In the last 15 years, it has been outpaced by younger and more agile rivals like the GAVI Alliance and the Global Fund to Fight AIDS, Tuberculosis and Malaria (Global Fund), whose very existence is seen as a reproach to the state-centric, bureaucratic and political WHO (2). Indeed, former Executive Director of the Global Fund Richard Feachem cited the decision to establish the Fund as a foundation independent of the UN system as one reason for enabling this new entity to become a technical, evidenced-driven entity. He described the Fund as a "very apolitical organization... (where) weve been able to take principled and technical decisions which haven't always been popular because we're not subject to the political influences that would come to bear in the UN" (5).

While the WHO certainly has its fair share of problems and continues to struggle in reforming its operations (3), it is not alone among the array of global health organisations subject to political pressures. Politics is also at the heart of newer organisations that claim to be driven by evidence and technical know-how (6). Feachem, himself "no boring bureaucrat or cautious political operator" (7), has been credited with having had an extraordinary influence on global health politics $(7,8)$. For example, when faced with impending dissemination of early findings from the first independent research on the effects of the Global Fund on recipient countries' health systems in 2003, his Secretariat sought to influence and control the message and how it was disseminated, which included putting pressure on the European bilateral donor agencies that were funding the research (9). Politics at its most basic is about influencing others. Moreover, politics is not distinct from nor carries on in parallel to policy, despite sometimes being treated as such. For better or worse, political dynamics play a critical role in shaping global health policy processes and cooperation, and are part of the ebb and flow of changing political fortune.

\section{The GAVI Alliance: Politics in partnerships}

The GAVI Alliance was officially launched at the beginning of 2000, a public-private partnership involving the WHO, UNICEF, donor and implementing governments, the Bill \& Melinda Gates Foundation (Gates Foundation) and other select non-state actors. It emerged on the back of substantial donations from the Gates Foundation, followed by further commitments from a small number of major donor governments. The new organisation followed on the heels of the taskforce for Child Survival and the Children's Vaccine Initiative (CVI), and introduced new forms of financing and governance that would later be adapted by other organisations (10). Up to 2008 , it was an incorporated public-private partnership hosted by UNICEF, with the 501(c) (3) charity Vaccine Fund that financed its operations based in Seattle. The Vaccine Fund was effectively under the direction of staff associated with the Gates Foundation Child Vaccine Program (CVP) hosted by PATH in Seattle, a NGO closely associated with the Gates Foundation.

As Bill Muraskin suggests, it was evidence of a 'trust-in God-but-pass-the-ammunition' attitude among a small, but influential vaccine policy community towards partnering with UN agencies and some donors-an insurance policy for an ascendant vaccine community based on an attitude 
borne out of their frustration at the way in which multilateral and bilateral organisations work. This largely US-based community was critical of the underfunding and bad management of immunization programmes, which allowed rivalries to undermine earlier partnerships like the CVI, including obstructing efforts to bring the vaccine industry into these partnership processes $(11,12)$.

The contentious environment in which GAVI emerged was fuelled by competing ideas and evidence on how best to increase immunisation coverage levels. Some saw a critical need to develop new vaccines; to verticalise and thereby strengthen the delivery architecture for these and underused vaccines; and to include non-state actors, primarily industry, in these processes. The conflicting view came from those who considered broader health sector reform as a means to improving immunization services, where immunization services would be supported and improved only in the context of public health systems development; and that prioritising the hard to reach, the poor and other neglected populations with existing vaccines took priority over investing in and rolling out new vaccines. The health reform and systems advocates were the more powerful policy community during the 1990s, though they may not have been alert to the ascendency of a small, hidden but powerful vaccine community that had developed strong ties to the well-resourced Gates Foundation during the latter years of the decade.

In a report from a meeting organised by the WHO Department of Vaccines and Biologicals on health sector reform and immunization held in Washington on the eve of GAVI's launch, those favouring priority vertical immunization programmes, "who may feel threatened or devalued during health sector reform/development" were advised that their "pro-active engagement and support is likely to prove a more effective response than maintaining a distance, which may risk loss of influence" (13). Within a couple of years however, with the establishment of the GAVI Alliance and then the Global Fund, it was donors and multilateral agencies promoting health sector reforms that were in danger of losing influence as the tide turned in favour of priority interventions, selected targets and engaging a wider set of actors beyond traditional state systems.

\section{The Global Fund: Product of a very political process}

While different in genesis, the emergence and evolution of the Global Fund was formed in an equally political climate, and following in the footsteps of the GAVI Alliance, moved global health into what Lidén terms an 'age of grand ambitions' (14). Following decades of insufficient action against the growing crisis and needless personal tragedies inflicted on millions by HIV and AIDS, a range of coalitions eventually found a way to break through the inertia. While the major timeline events leading up to the launch of the Global Fund are by now well documented (14), behind the scenes and in the run up to the launch different coalitions sought to shape the structure and policy priorities of the emerging organisation.

For example, donor governments, far from being internally coherent not to mind a coherent bloc, were developing parallel approaches. Engaged in negotiations on what a new initiative might look like, the Canadian International Development Agency (CIDA), the UK Department for International Development (DfID), and USAID coalesced into the 'Ottawa Group' in 2000. This group sought to develop what they termed a 'health systems response' to communicable diseases, focusing in particular on HIV/AIDS, TB, malaria and communicable diseases of childhood, with the proposed Ottawa Fund having a state-centric governance structure (15). Also in 2000, the United States established a World Bank AIDS Marshall Plan Trust Fund Act (16). This Trust Fund was to be administered by the World Bank and governed by a Board of Trustees composed of representatives from participating donor countries, as well as pharmaceutical companies willing to donate to the Trust Fund. Governments and NGOs would be eligible for grants, which could be used for prevention, education, treatment, and care activities.

In the period coming up to the Global Fund launch, NGOs had gained a degree of acceptance as part of the global health policy environment. With negotiations for a new initiative underway by May 2001, representatives from several NGOs directly entered the political foray and advocated for the new initiative to be a procurement fund for AIDS treatment. Many NGO representatives were driven by a belief that donors were manoeuvring to avoid committing to funding treatment, a belief that had basis in fact. For example, concerns were expressed about funding anti-retroviral treatment at the UK Development Committee meeting in Sep 2001, where many at this meeting "agreed that the 'Anti-retroviral' solution to the HIV/AIDS problem was impractical, especially in Africa, even as part of an overall scheme. If deployed by the [Global Health Fund] widely the budget would be rapidly depleted, but if rationed out to developing countries, the rich would benefit at a disproportionate level to the poor" (17). Minutes of this meeting also noted that some members anticipated that NGOs would 'attempt to exert pressure to introduce ART as the [Global Health Fund's] primary tool for combating HIV/AIDS', which presumably needed to be resisted.

The division between prevention and treatment was a major point of tension between different groups, but it was a division that also existed within agencies like DfID, and which required senior personnel with substantial social skills for interpreting their environments, mobilising others to overcome differences and, thereby change the position of the organisation. The events described above are only a small sample of the micro-level political processes taking place in the run up to the launch of the Global Fund in 2002. The end settlement of all of these processes was a watershed by any standards, with the Global Fund Framework Document managing to capture many of the different positions and priorities of the stakeholders. Crucially, it led to the creation of an organisation that gave Board positions and voting rights to NGOs on a par with governments. Various political fault-lines came to be embedded in this document and would emerge at different times as the Global Fund evolved, including around ongoing tensions between placing emphasis on disease-specific or health systems approaches, an issue that would surface later in the 2000s in the GAVI Alliance as well (10). The resultant Fund was a platform that included a Board 
and committee structures that enabled politics to be played out but contained behind closed doors; and a Secretariat that was led by a politically adept Executive Director, who sought to impose a model of working that was less concerned about treatment versus prevention and more concerned with driving results through performance-based funding.

Ooms and Hammonds (18) describe a natural tension between public health research and the right to health - a tension between an 'appeal to tradition' and an 'appeal to faith' For instance, right to health researchers, practitioners and advocates tend to challenge the practice of designing health policies premised on assumptions of a status quo in financial resources, a position they attribute to public health researchers. This public health 'appeal to tradition', Ooms and Hammonds suggest, underpinned the shift from comprehensive to selective primary healthcare, the latter considered a more cost-effective option in a context of limited financial resources during the 1980s. This natural tension can similarly be applied to different actors in the case of the Global Fund outlined above.

The 'appeal to tradition' was echoed in the position of some donors in their response to HIV and AIDS who, while recognising that comprehensive HIV prevention and AIDS treatment would be the optimal strategy, constrained their ambitions and initially prioritized prevention as an interim strategy until additional resources became available. It also suggested a lack of faith in the capacity of recipient governments and communities affected by AIDS to scale up treatment. In the end, this conservative position was rejected, and the 'appeal to faith' became an empirical reality, in that treatment scale-up was being achieved - as it turned out, faith was justified in the face of the sceptics. Sustained pressure to substantially increase funding and re-draw the boundaries of what was possible and what ought to be done was realized through intensive political processes, with the newly formed Global Fund supporting and incentivising comprehensive government strategies that included AIDS treatment as well as HIV prevention.

\section{Global health policy as political process}

Global health policy has the aim of improving population health at a global level. This can only be achieved, however, through engaging in political processes involving actors and ideas, through strategic actions these actors take, the institutional structures that enable or constrain their actions, and in the circumscribed political environments in which decisions are made and health policies are implemented. And like all political processes, natural tensions-often between organisations and individuals that share the same goalsometimes lie dormant and other times surface in ways that can undermine the shared aims of even the closest of allies.

Much of public health and health policy research remains largely concerned with measuring and evaluating policy impacts and outcomes and presenting recommendations for policy choices (19). Politics is treated as distinct from policy, an unwelcome ghost that causally interacts with the policy machine, disturbing rational decision-making and technical intervention. However, political and institutional factors are central to global health policy processes, down to and including the development and use of health evidence (19-21). Politics is of fundamental importance to public health researchers and requires at least a willingness to analyse, even where there is a reluctance to engage in, the politics of public policy.

A wide range of frameworks, each contested in their own right, are available to policy researchers to assist in understanding the complexity of political processes in global health policy. Longstanding theories on institutional rational choice, multiple-streams, punctuated-equilibrium, and advocacy coalition frameworks have been supplemented by more recent understandings of the role of networks in political processes and how people make and bring about political change or act to stabilize existing hierarchical orders (22). Despite being viewed by some as beyond the remit of public health research, the political is an enduring feature of global health policy, and therefore of health policy analysis. And whether researchers like it or not, we too are part of these political processes, generating evidence that aims to influence decision-making where such decisions are never politically neutral or without consequence.

Ethical issues

Not applicable.

Competing interests

The authors declare they have no conflict of interest.

\section{Authors' contributions}

$\mathrm{CB}$ and RB conceptualised and designed the document; $\mathrm{CB}$ drafted and edited document; $C B$ and $R B$ revised and edited the document; $C B$ and RB agreed final draft.

\section{Authors' affiliations}

1Department of Epidemiology \& Public Health Medicine, Royal College of Surgeons in Ireland, Dublin, Ireland. 'Division of Population Health Sciences, Royal College of Surgeons in Ireland, Dublin, Ireland.

\section{References}

1. World Health Organization (WHO). Framework of Engagement with non-State Actors - Report by the Secretariat (5 May), 2014.

2. Hawkes N. "Irrelevant" WHO outpaced by younger rivals. BMJ 2014; 343: d5012. doi: 10.1136/bmj.d5012

3. Clift C. The Role of the World Health Organization in the International System. London: Chatham House; 2013.

4. Chow JC. Is the WHO becoming irrelevant? [internet]. 2010. Available from: http://www.foreignpolicy.com/articles/2010/12/08/ is_the_who_becoming_irrelevant

5. PBS. Interview: Richard Feachem. 2005 [cited 2014 May]. Foreign Policy 8 Dec. Available from: http://www.pbs.org/wgbh/ pages/frontline/aids/interviews/feachem.html

6. Barnes A, Brown GW. The Global Fund to Fight AIDS, Tuberculosis and Malaria: Expertise, Accountability and the Depoliticisation of Global Health Governance. In: Williams O, S Rushton, editors. Global Health and Partnerships and Private Foundations: New Frontiers in Health and Health Governance. Basingstoke: Palgrave Macmillan; 2011. p. 53-75.

7. Rivers B. Board Assignment - Find a Leader Who Is Remarkable in New Ways [internet]. Global Fund Observer 2006; 55. Available from: http://www.aidspan.org/gfo_article/board-assignment-findleader-who-remarkable-new-ways

8. Das P. Richard Feachem: Scaling the heights of global health leadership. Lancet 2010; 376: 1533. doi: 10.1016/S0140- 


\section{6(10)62018-1}

9. Walt G, Shiffman J, Schneider H, Murray SF, Brugha R, Gilson L. 'Doing' health policy analysis: methodological and conceptual reflections and challenges. Health Policy Plan 2008; 23: 308-17. doi: 10.1093/heapol/czn024

10. Harmer A, Bruen C. The GAVI Alliance. In: Hale T, D Held, editors. Handbook of Transnational Governance: New Institutions and Innovations. London: Polity Press; 2011. p. 384-94.

11. Muraskin W. The Last Years of the CVI and the Birth of GAVI. In: Reich M, editor. Public-Private Partnerships for Public Health. Cambridge, MA: Harvard Centre for Population \& Development Studies; 2002. p. 115-68.

12. Muraskin W. Crusade to Immunize the World's Children. Los Angeles: USC Marshall Global BioBusiness Initiative; 2005.

13. World Health Organization (WHO). Report of a meeting on health sector reform and priority health interventions: the case of immunisation services. Washington 15-16 Nov 1999. Washington, DC: WHO Department of Vaccines \& Biologicals 2000.

14. Lidén J. The Grand Decade for Global Health: 1998-2008. Chatham House Working Group on Governance. London: Chatham House; 2013.

15. Ottawa Group. Report on the Follow Up to the Ottawa Meeting, 15-16 Feb 2001
16. House of Representatives, United States 106th Congress. House Report 106-548 - World Bank AIDS Marshall Plan Trust Fund Act (H.R. 3519), 2000.

17. UK Development Committee. Minutes of the UK Development Committee, 20 Sep 2001.

18. Ooms G, Hammonds R. Right to health and global public health research: from tensions to synergy? Trop Med Int Health 2014; 19: 620-4. doi: 10.1111/tmi.12287

19. Bernier NF, Clavier C. Public health policy research: making the case for a political science approach. Health Promot Int 2011; 26: 109-16. doi: 10.1093/heapro/daq079

20. Liverani M, Hawkins B, Parkhurst JO. Political and institutional influences on the use of evidence in public health policy. A systematic review. PLoS One 2013; 8: e77404. doi: 10.1371/ journal.pone.0077404

21. Barnes A, Parkhurst J. Can Global Health Policy be Depoliticized? A Critique of Global Calls for Evidence-Based Policy. In: Brown GW, G Yamey, S Wamala, editors. The Handbook of Global Health policy. New Jersey: John Wiley \& Sons, Ltd; 2014. p. 158-73.

22. Brugha $\mathrm{R}$, Bruen $\mathrm{C}$, Tangcharoensathien $\mathrm{V}$. Understanding Global Helath Policy. In: Brown GW, G Yamey, S Wamala, editors. The Handbook of Global Health Policy. New Jersey: John Wiley \& Sons, Ltd; 2014. p. 21-45. 